\title{
La relación bilateral chileno-boliviana a partir de las demandas tarapaqueñas: aproximación teórica desde la paradiplomacia como heterología*
}

\author{
Bilateral relations between Chile and Bolivia from the \\ perspective of Tarapaca's demands: a theoretical \\ approach from paradiplomacy as heterology
}

\author{
Cristián Ovando Santana** \\ Sergio González Miranda***
}

\section{Resumen}

Este trabajo aborda las relaciones entre Chile y Bolivia desde 1904, año del Tratado de La Paz, y la década de 1960, cuando surge el conflicto por las aguas del río Lauca. Se analizan algunos hitos integracionistas emprendidos desde las regiones contiguas de Tarapacá-Arica y Oruro, donde se puede observar la tensión entre región y Estado nacional.

El análisis se centra en el protagonismo de una pluralidad de actores políticos y sociales que promovieron y le demandaron al Estado central una mayor integración con Bolivia. Se sostiene que dichas demandas configuraron un proyecto político regional transfronterizo en el período señalado. Se pretende escudriñar en los alcances y limitaciones de una serie de prácticas regionales de alcance internacional, opacadas o silenciadas por la diplomacia oficial, interpretadas desde la perspectiva

Artículo resultado del Proyecto Anillos SOC 1109, CONICYT: «Relaciones transfronterizas entre Bolivia y Chile: Paradiplomacia y prácticas sociales 1904-2004»

Recibido el 4 de septiembre de 2013; aceptado el 3 de diciembre de 2013.

** Académico del Instituto de Estudios Internacionales de la Universidad Arturo Prat. covando@unap.cl

**** Director del Instituto de Estudios Internacionales de la Universidad Arturo Prat. sgonzale@ unap.cl 
de la paradiplomacia como relación social o heterología.

PAlabras Clave: proyecto político regional, diplomacia estatal, paradiplomacia, relaciones trasfronterizas.

\section{Abstract}

This paper addresses relations between Chile and Bolivia since 1904, year of the Treaty of Peace, and the 1960s, when conflict arises over the use of the waters of the Lauca River. Some integrationist historical events embarked in the adjoining regions of Tarapacá-Arica and Oruro, where the tension between region and nation-state can be observed are examined.

The analysis focuses on the prominence of a diversity of political and social actors from the central states that encouraged and demanded greater integration with Bolivia. It is contended that those demands formed a cross-border regional political project in that period. The idea is to examine the significance and limitations of a series of regional practices of international significance, overshadowed or silenced by the official diplomacy, from the perspective of paradiplomacy as a social relationship or heterology.

KEYWORDs: diplomacy, paradiplomacy, cross-border relationships, regional political project. 


\section{INTRODUCCIÓN}

Las relaciones bilaterales de Chile y Bolivia, en el amanecer del siglo veinte, parecían por fin tomar un rumbo de normalidad y buena vecindad. Una de sus características fue que los Estadosnacionales recurrían a la diplomacia estatal para resolver sus litigios, dejando atrás el conflicto diplomático acontecido en el tercio final del siglo diecinueve, después de la Guerra del Pacífico, que solamente había permitido un Pacto de Tregua en 1884. Sin profundizar en los entretelones que permitieron el Tratado de Paz y Amistad de 1904, fue este un momento de inflexión, donde las miradas de los Estados-nacionales coincidieron con los intereses empresariales de la época (González, 2004), mayoritariamente relacionados con la economía minera de ambos países. El territorio que había estado en litigio comenzó a ser visto como un espacio relativamente integrado, donde los flujos podían articularse a través de líneas férreas que, a su vez, expresaban la modernidad tanto en Chile (Castro, 2003) como en Bolivia (Gómez ,1998).

Hacia 1904 la diplomacia estatal chilena cumplía su papel más relevante desde 1884, cuando se ratificó el Tratado de Paz y Amistad con Perú, conocido como de Ancón. Ahora era Bolivia el país con el cual se debía cerrar lo que había quedado pendiente durante la larga postguerra del Pacífico. Los términos de este nuevo acuerdo internacional venían discutiéndose desde 1902, a partir de la gestión del diplomático boliviano y empresario minero, Félix Avelino Aramayo (Milet, 2004:40). Las expectativas que surgieron en Bolivia por este acuerdo fueron muy altas, especialmente entre los empresarios mineros, porque incluía no solo compensaciones económicas y el reconocimiento de las inversiones en uno y otro país, sino también la construcción del ferrocarril entre Arica y La Paz que junto al ferrocarril ya existente entre Antofagasta y Oruro articulaban todo el occidente de Bolivia con el litoral del Pacífico, entre Arica y Antofagasta. La idea de que los puertos chilenos fueran una plataforma exportadora que proyectara a los productos bolivianos en el mercado internacional, y que a su vez aproximara los bienes y servicios mundiales al mercado interno boliviano, no solo estimulaba la imaginación en ese país, sino también la de las regiones del Norte Grande de Chile, especialmente Tarapacá. Irónicamente, el puerto de Tarapacá, Iquique, era el único que no estaba integrado físicamente con Bolivia a través de una línea férrea, a pesar de los distintos proyectos presentados al gobierno central para alcanzar ese anhelo. La frustración generada por el fracaso recurrente de esos proyectos se transformó en un acicate hasta volverlo en un verdadero proyecto político de desarrollo regional (González, 2011), como el presentado por Carlos Harms Espejo al Gobierno de Carlos Ibáñez del Campo en 1928 (Harms, 1930).

Una hipótesis posible del por qué se frustraron los proyectos de integración física transfronterizos emprendidos a 
partir de Tarapacá es lo que algunos autores han denominado el «síndrome holandés» (Jeftánovic, 1992), no solo en el sentido de que la expansiva industria salitrera desincentivó otras actividades económicas, sino porque impidió que las autoridades centrales comprendieran el sentido de la demanda regional por cambiar el modelo económico de desarrollo existente por uno que estuviera basado más en el comercio internacional, donde la minería fuera solo uno de sus eslabones. No parecía necesario para las autoridades centrales ese cambio si se estaba en plena expansión de la economía del nitrato y Tarapacá era la provincia principal. Los vecinos de Iquique pensaban distinto y no escatimaron esfuerzos por convencer a las autoridades centrales que se construya una línea férrea hacia Oruro, en la búsqueda de otros minerales o tras la producción agropecuaria boliviana, complementado con el hecho de que en Oruro se pensaba en el mismo proyecto ferroviario.

En 1913 comenzaron a sentirse los primeros síntomas de agotamiento de la economía salitrera, lo que justificaba aún más las demandas tarapaqueñas a los presidentes Germán Riesco y Pedro Montt, que habían quedado guardadas en los cajones de sus respectivos gabinetes, ameritando incluso la visita a Tarapacá y Antofagasta de una Comisión Parlamentaria, compuesta por los diputados Enrique Oyarzún, Ismael Vicuña, J. Enrique Costa, Ruperto Álamos, Francisco Vidal y Nolasco Cárdenas. Esta Comisión no imaginó la profundidad de la crisis del año siguiente, 1914 (Couyoumdjian, 1986), pero para fortuna de las provincias salitreras la Primera Guerra Mundial le entregaría una tabla de salvación a esta industria al demandar nitrato refinado para fines bélicos, generando un nuevo impulso a esta economía a partir del segundo semestre de 1915 .

Otro aliciente fue que, coincidentemente con el término del proyecto ferroviario Arica-La Paz, en noviembre de 1913 Chile logró por fin articular una red ferroviaria longitudinal desde Tarapacá hasta Llanquihue. Entonces surgió la idea de una conexión ferroviaria entre Tarapacá y Arica, lo que implicaba extender líneas desde Pintados hasta Poconchile. Empero, este fue otro proyecto tarapaqueño frustrado.

En el campo diplomático tradicional, el realismo que llevó a la firma del Tratado de 1904, abriendo las puertas a un proceso de integración física y complementación económica, comenzó a cambiar en Bolivia a partir de 1919, año en que «el gobierno boliviano le introdujo un elemento que enfrió los entusiasmos a orillas del Mapocho: la revisión de los Tratados. Fue una idea de Ismael Montes, itinerante servidor público boliviano, ese año en París como Ministro Plenipotenciario, que acogió y dio forma de circular el Ministro de Relaciones Exteriores Alberto Gutiérrez, para anunciar una próxima petición de revisión del tratado de 1904, en el marco de las ideas recién comunicadas por la Sociedad de Naciones» (Pinochet de la Barra, 2004:39). Según 
Jorge Escobari Cusicanqui, "Chile se disgustó por el hecho de que Bolivia hubiese llevado su demanda a la Liga de las Naciones» (1978:155). Por cierto, esta demanda no estaba desvinculada del contexto internacional generado por la visión de Woodrow Wilson sobre los conflictos y la paz mundial. A partir de este momento, se puede afirmar que se inicia formalmente la demanda boliviana por un acceso soberano al océano Pacífico después de haber suscrito el Tratado de 1904.

Jaime Eyzaguirre, el historiador chileno, resume así este momento: «El segundo paso le tocaría darlo al general Ismael Montes, que como Presidente de Bolivia sancionó el Tratado. Ahora en su calidad de Ministro Plenipotenciario en Francia, elevó una nota a su gobierno, el 14 de enero de 1919, para alegar derechos preferentes de su patria en Tacna y Arica y anunciar que los haría valer ante la Liga de las Naciones. Una Circular del Canciller de Bolivia don Alberto Gutiérrez, firmante del convenio de 1904, dirigida a la representaciones diplomáticas de su patria, el 24 de febrero de 1919, vino a complementar el paso del general Montes y a desarrollar la tesis de la revisión de los tratados y del derecho a puerto de Bolivia. El Perú, sintiéndose aludido, respondió con otra circular, de 30 de abril del mismo año, protestando de las aspiraciones bolivianas sobre territorios que juzgaba propios» (1963:51-52). Por su parte, el historiador boliviano, Jorge Escobari Cusicanqui, lo hizo de este modo: «El 14 de enero de 1919, el general Ismael
Montes, Ministro de Bolivia en París, por instrucciones de su gobierno envió una nota al Gobierno de Francia y un memorándum a la secretaría de la Liga de las Naciones. En la nota después que expresar que Bolivia considera que tiene también derechos con respecto a Tacna y Arica, decía que sus razones «se apoyan en la historia y la tradición», así como "en la situación geográfica de Bolivia que hace de Arica su salida obligatoria al exterior» (1979:91).

Esos años fueron particularmente complejos para Chile. En 1920 asumió la presidencia Arturo Alessandri Palma, quien se propuso resolver el conflicto con Perú por Tacna y Arica, al destacarlo entre las medidas más urgentes de su gobierno, quedando Bolivia en un papel denominado "tercería boliviana». A pesar del interés de Alessandri por resolver el conflicto de Tacna y Arica, la solución recién pudo llegar en 1929 con el Tratado de Lima, pero abrió la ventana a un nuevo problema: el protocolo complementario de dicho Tratado que impide a Perú y Chile ceder a una tercera potencia parte o la totalidad de los territorios de Tacna o Arica sin consulta al otro país. Acuerdo que sería conocido como «la llave y el candado».

A escala regional y transregional, la década siguiente abrió una nueva etapa: 1. Porque la economía salitrera entra en su fase terminal generando una emigración de retorno de quienes habían llegado al desierto de Atacama, incluyendo a la población boliviana; 2. La provincia de Arica, que siempre estuvo vinculada e integrada a Tacna, 
pasó a formar parte de Tarapacá, germinándose uno de los conflictos intrarregionales más conocidos en Chile ${ }^{1}$; 3. La frontera chileno-boliviana, con la declinación de la economía salitrera, dejará de ser porosa para comenzar a ser más controlada.

Al cierre de las fronteras que la economía minera había abierto para abastecerse de mano de mano de obra y de bienes de consumo humano e industrial, parecía también acompañarle el término de los proyectos de integración física a través de líneas férreas, que habían movilizado a la población regional por más de medio siglo. Sin embargo, al contrario, el movimiento regional comenzó a elaborar un discurso enfocado en un camino internacional hacia Bolivia para camiones de alto tonelaje.

Fue en este momento histórico cuando, por un lado, agrupaciones sociales de variada índole de las provincias contiguas de Bolivia y Chile entraron en colisión con la diplomacia tradicional o estatal y, por otro, las perspectivas de desarrollo regionales demandaron atención de las nacionales. El regionalismo construyó un discurso cada vez más orientado hacia el problema transfronterizo, donde los corredores bioceánicos fueron la expresión más notoria. Sin embargo, el discurso diplomático oficial se impondrá hegemónicamente en el sentido de que, sin violencia manifiesta, copó todo el campo semántico de las

1 En 2006 bajo el Gobierno de Michelle Bachelet se creó la región de Arica-Parinacota, respondiendo a una demanda histórica de esa comunidad. relaciones bilaterales, invisibilizando o silenciando las demandas locales a través de un control de los liderazgos y de sus reivindicaciones. Un ejemplo del aprovechamiento de esos espacios diplomáticos intersticiales que permitieron la emergencia de demandas regionales transfronterizas a uno y otro lado de la frontera, fue el caso de las caravanas de la amistad de 1958 (González 2012), cuando las elites políticas y sociales de Oruro y Tarapacá, aprovechando la aproximación entre los gobiernos de Hernán Siles Suazo y Carlos Ibáñez del Campo, de Bolivia y Chile respectivamente, decidieron unir a las dos regiones utilizando los viejos caminos existentes en una aventura de ida y vuelta, que marcó un hito transfronterizo regional, para demostrarles a sus respectivos gobiernos la necesidad de esa conexión vial. Los gobiernos nacionales reaccionaron positivamente, pero los cambios de gobiernos en ambos países no solo frustraron este proyecto sino que emergerá en 1962, desde La Paz, lo que se conocerá como «el conflicto del Lauca».

En otras palabras, cada vez que las diplomacias estatales de ambos países tendían a coincidir, volvían las demandas regionales en pos de la complementación económica. Empero, esos momentos de acercamiento diplomático no fueron lo suficientemente sólidos y permanentes en el tiempo como para alcanzar objetivos concretos. Posiblemente uno de ellos fue la construcción del oleoducto Sica Sica, claramente 
beneficioso para Bolivia ${ }^{2}$ y que Arica nunca ha puesto en cuestión.

El objetivo de este trabajo es en interpretar algunos hitos del desarrollo de la diplomacia bilateral chilenaboliviana, entendida como heterología o relación social; es decir, teniendo en cuenta un pluralismo diplomático que dé cuenta de una interrelación transfronteriza tanto entre regiones contiguas como desde las respectivas capitales, desde el Tratado de Paz y Amistad de 1904 hasta el conflicto diplomático por las aguas del río Lauca. Nos adentraremos, por tanto, en el estudio de un caso específico: la región fronteriza de Tarapacá y sus vínculos con regiones vecinas de Bolivia.

En lo referido particularmente a lo disciplinario, proponemos un enfoque teórico sobre estudios diplomáticos que encuadra en el denominado cuarto debate de las relaciones internacionales. En concreto, discutimos desde una corriente crítica sobre los estudios diplomáticos (Constantinou, 2013; Der Derian, 1987; Cornago, 2013), que adhiere a las denominadas corrientes reflectivistas de la disciplina (Salomón, 2002). Consideramos que este enfoque puede ser apropiado para abordar el fenómeno estudiado, pues busca el regreso crítico al pasado en que se inscriben esas prácticas diplomáticas. Sin perjuicio de lo anterior, reconocemos la importancia que ha tenido el enfoque

La prensa de ese país contraria al proyecto del gasoducto hacia el puerto de Patillos no hizo referencia a esta obra. realista en el quehacer diplomático mismo, tanto en Bolivia como en Chile. Abordaremos distintas actividades vinculadas al desarrollo transfronterizo de Tarapacá emprendidas por actores paradiplomáticos y diplomáticos de ambos países, desde el significado que le dan los propios actores a dichas actividades. En efecto, las demandas políticas y económicas regionales se conciben como reivindicaciones endémicas en tanto han persistido en el tiempo, en este caso, como lo hemos señalado en escritos anteriores (González 2011), desde 1864 en adelante. Aquí lo relevante es problematizar la construcción social y cultural de una identidad regional a partir de un proyecto político de desarrollo (Boisier 2004:37), aunque haya sido sobre la base de fracasos (como los proyectos ferroviarios transfronterizos) recurrentes. De todos modos se generó un capital social y cultural que ha permitido la persistencia de esa idea (la integración física transfronteriza) en las actuales regiones de Tarapacá y Arica-Parinacota hasta nuestros días (expresada en los corredores bioceánicos).

\section{Diplomacia bilateral COMO HETEROLOGÍA}

\subsection{Heterología y genealogía de la diplomacia}

En las últimas dos décadas ha surgido una corriente crítica sobre diplomacia que cuestiona la idea de que 
aquella esté reservada solo al Estado, al Ministerio de Relaciones Exteriores y a sus agentes autorizados (Constantinou, 2013). Esta perspectiva plantea superar la idea de que se trata de un arte «extremadamente formalizado y rígido, dentro una más amplia maquinaria de la política exterior del Estado, completamente aislado de las experiencias sociales reales, y privado de cualquier relevancia política inmediata de nuestra vida diaria» (Cornago,2013b: 7-18). Surge así una idea renovada sobre la diplomacia que toma en cuenta la subjetividad y el contexto histórico en que opera, entendida como el «distanciamiento entre seres humanos por poderes simbólicos y restricciones sociales» (Der Derian, 1987). Esta aproximación nos permite un espacio "para el entendimiento diplomático en las más diversas expresiones de la vida social»(Cornago, 2013b:11), dentro de las cuales destacamos para América del Sur las incipientes diplomacias subestatales o paradiplomacia (Aranda y otros, 2010), incluso las emergentes diplomacias indígenas y de los pueblos (Vargas, 2013). El aporte de este enfoque a este estudio sobre Tarapacá y sus proyectos transfronterizos, es que nos permite revisar el pasado y observar prácticas y actores que podríamos considerar (para)diplomáticos. ¿Cómo podríamos calificar la acción del Comité Pro-Camino Iquique-Oruro, el papel de Carlos Harms Espejo, en la década de los años 1920?

Solo a modo de ejemplo, veamos lo que señala el diario El Tarapacá de 11 julio de 1928, página 11, en un reportaje titulado «El anhelo de Tarapacá», escrito por Harms Espejo:

«Una vez más nos hemos propuesto desinteresadamente, poner la pluma al servicio de las conveniencias del país

Proponemos ahora, las mismas ideas que hemos sustentado en la prensa y que han sido felizmente acogidas como practicables por eminentes hombres de vasto criterio en la materia.

La ventajosa circunstancia de tener a cargo de la Suprema magistratura de la nación no un simple Gobernante, sino un superhombre que, con singular clarividencia se ha preocupado especialmente del futuro comercial y económico de la provincia de Tarapacá, ha sido un poderoso estimulo que nos ha impulsado a elevar hasta su alta consideración los diversos proyectos recomendables, unos más que otros, sobre la construcción del Ferrocarril Iquique-Oruro. Y por esa misma circunstancia opinamos que se ofrece la ocasión propicia para que se entable una encuesta por la prensa en que personalidades interiorizadas de la materia, opinen sobre los trazados y determinen el que debe prevalecer y dar margen al proyecto definitivo, que una Comisión, oficialmente designada, presentaría al Supremo Gobierno.

Podrán interesar al Gobierno y a los habitantes de un país, la conservación de cierto partido político, la reforma de sus leyes y el incremento mediante creaciones de economías de las arcas fiscales; pero nada en importancia y en fecunda labor al empeño que se despliegue en pro del engrandecimiento económico de regiones que auguren la más segura y favorable repercusión de la balanza 
financiera del país, como sucede con la de Tarapacá.

Lejos está de ser producto de mera fantasía lo que decimos de esta provincia. Hay razones de peso, basadas en imperiosas necesidades que exigen la realización de algunos de los trazados en estudio entre los puntos más arriba indicados. Esto so pena de acarrear fatalmente, por su no ejecución, azarosos años de despecho, ante prejuicios incalculables funestísimos en tiempo de guerra no solo regionales sino generales, y aún haciendo codiciar el florecimiento de la República Argentina, que afana en seguir atrayendo la corriente comercial más importante de Bolivia.

En el presente folleto probaremos lo expuesto y, basando las materias, sobre todo las referentes a las riquezas minerales y agrícolas existentes entre Oruro e Iquique, en conocimiento y apreciaciones autorizadas, habremos puesto nuestro estudio y criterio al servicio de los intereses generales del país y del Supremo Gobierno, quien ha de encomendar a los técnicos el proyecto definitivo sobre la vía férrea que haya de proporcionar a Bolivia salida hacia el Océano Pacífico...»

Este último párrafo, el General de Ejército en retiro, Carlos Harms Espejo, sin duda, lo escribió con la convicción de que a partir de una idea de complementación económica entre las localidades de Oruro e Iquique resolvía también el problema bilateral entre Bolivia y Chile. Su propuesta fue una de las más completas y meditadas sobre el desarrollo de Tarapacá y, por añadidura, del Norte Grande de Chile y del occidente de Bolivia, que se haya conocido hasta la actualidad ${ }^{3}$. Solo comparable con la que realizara el destacado académico y político boliviano Ricardo Anaya, en la década de 1980, bajo el título «Arica trinacional. Bolivia, Chile y Perú, una fórmula de paz, integración y desarrollo» ${ }^{4}$.

Anaya planteaba entonces que «las universidades y otros centros de investigación y planificación de Bolivia, Chile y Perú podrían tomar a su cargo el estudio de la idea, en sus distintas proyecciones y levantar investigaciones de los factores económicos, sociales y culturales que intervienen en el problema, así como sugerir las modalidades que se podrían imprimir a las respectivas soluciones. Tales estudios podrían comprender el inventario de los recursos naturales de la zona, los sistemas de complementación económica que fuesen aconsejables; los mercados, la ampliación y diversificación de estos no solo dentro del Área, sino en sus vinculaciones con los mercados de los países limítrofes y aun del Continente» (1987:82). Este ex canciller de Bolivia apelaba, para buscar una solución al problema marítimo de su país, a las universidades y centros de estudios, a la complementación económica y a un inventario de los recursos naturales, es decir, por un lado, confiar la tarea a

3 En 1930 la Editorial La Ilustración de Santiago, publicó su trabajo en un libro titulado «Los grandes problemas de la zona norte de Chile».

4 Obra que sería publicada en 1987 por la Editorial Los Amigos del Libro, en La Paz y Cochabamba. 
actores no diplomáticos oficiales y, por otro, realizar lo que Harms Espejo ya había efectuado cuatro décadas antes.

Esta mirada del pasado en búsqueda de otros actores diplomáticos, con el propósito de ampliar las posibilidades de solución a problemas entre países o entre regiones, es lo que entendemos por diplomacia como heterología.

Por heterología nos referimos a las prácticas diplomáticas -desde una comprensión reflexiva y normativaque tomen en cuenta las implicaciones de su compromiso con el "otro" diplomático (Cornago, 2013:33,34). Por «otro" diplomático, entendemos a una pluralidad de actores sociales no necesariamente oficiales ${ }^{5}$ que participan a distinta escala y se constituyen en un lugar para el entendimiento humano y la reconciliación política (Cornago, 2013b). Esta posibilidad estaría dada a partir de evidencias de "prácticas de comunicación entre comunidades tal como se han experimentado a lo largo de la historia en diferentes contextos locales (Constantinou, 2010, citado por Cornago, 2013b:2), como es el caso estudiado aquí de Tarapacá y Oruro.

Para demostrar la acción de actores nodiplomáticos pero simbólicamente relevantes en pos de la integración entre Tarapacá y Oruro, tenemos el caso de Horacio Amaral, quien fuera un destacado visitador de escuelas de la Provincia de Tarapacá, presidiendo el Comité Pro-Camino de Iquique a Oruro, creyendo en la factibilidad de este proyecto en septiembre de 1934, en plena crisis económica (ver: Archivo de Intendencia de Tarapacá. Copiadores de oficios. Año 1934, s/fojas).
Prácticas que se alejan de la actividad diplomática oficial que tradicionalmente han ejercido los Estados latinoamericanos desde su fundación. Sin embargo, siguiendo las evidencias históricas esas prácticas paradiplomáticas son anteriores o se han desarrollado de forma paralela a las diplomáticas. Creemos que fueron prácticas paradiplomáticas los casos de los diferentes Comités creados en Arica ${ }^{6}$, Iquique ${ }^{7}$ y Antofagasta ${ }^{8}$ en pos del desarrollo regional o para la creación de caminos internacionales en pos de una integración física transfronteriza.

Por otra parte, en la misma tendencia normativa, adherimos a la denominada diplomacia sostenible, aquella que "plantea una comprensión profunda de la relación que una población tiene con su tierra, sus tradiciones religiosas y culturales, su realidad ecológica y sus vecinos» (Constantinou 2010 citado por Cornago, 2013b:2), una vez más: como es evidente en el caso de los habitantes de Tarapacá y su vecina Oruro, donde la historia colonial y el territorio les identifican, ni siquiera la cordillera de los Andes ha sido obstáculo para sus intentos de integración física. Un ejemplo simbólico es el vínculo entre el carnaval de Oruro y la fiesta religiosa de La Tirana, donde las bandas de bronce

6 Comité Pro-Resurgimiento de Arica, constituido el 5 de febrero de 1932.

7 Comité de vecinos de Iquique 1902; Comité Pro Camino de Iquique-Oruro 1928. 8 Comité Pro-Ferrocarril a Salta (Zaldivar 1923). 
y las diabladas ${ }^{9}$, entre otros elementos, tienen origen en la región boliviana.

Rescatar cierta pluralidad de actividades (para)diplomáticas apelando a la singularidad de casos que han pasado inadvertidos para la historia diplomática oficial pasa por adentrarnos en escalas diferentes de la nacional, como aquella a que se refiere Bob Jessop (2004), que puede ser definida como «escala transfronteriza». Sostenemos que, como el caso de Tarapacá y Oruro, si bien se trata de regiones de países distintos y, por lo mismo, están bajo el signo de la política exterior de ambos Estados nacionales donde la escala que prevalece es la nacional. Nos encontramos con regiones que existieron antes de la construcción de ambos Estados nacionales y que tuvieron relaciones comerciales y culturales durante la Colonia en torno al eje minero de Potosí, por un periodo más largo que el actual de las respectivas repúblicas, formando parte de un territorio más amplio que Carlos Sempat Assadourian denominó «espacio peruano» (1982).

Sin perjuicio de lo anterior, no creemos que estas regiones puedan calificarse dentro de aquellas que, producto de su difícil relación con el centro político, hayan sufrido una "alienación territorial»( Cornago,2013) o sentimiento de abandono y postergación del territorio y sus habitantes, que a veces también configura una reivindicación identitaria

9 La primera diablada en Tarapacá, como cofradía y no como figurines sueltos, se organizó después de la caravana de la amistad de 1958 (González 2012). y estimula la expresión de actividades paradiplomáticas en regiones periféricas, sobre todo en Estados unitarios centralizados. Aunque en Iquique se haya realizado una de las huelgas obreras más emblemáticas de la Historia de Chile ${ }^{10}$, e inaugurado la protesta social a través de banderas negras ${ }^{11}$, sostenemos que la demanda de integración física con Bolivia, desde la construcción de un ferrocarril hacia Oruro hasta el actual corredor bioceánico, responde a un proyecto político de desarrollo enmarcado en lo que Boisier denomina «regiones asociativas de frontera» (2004:35). En este punto, hacemos hincapié en la necesaria complementariedad teórica entre las disciplinas de los estudios regionales con aquellas de los estudios internacionales y diplomáticos.

Conjeturamos que la complementariedad presente a lo largo del siglo XX entre distintos actores (para) diplomáticos chileno- bolivianos respondería a la particularidad territorial de Tarapacá y Oruro, de cómo se han apropiado de dicho territorio distintas subjetividades provenientes de diferentes escalas de acción, donde la transfronteriza tendría una importancia estratégica.

Planteamos que la diplomacia como heterología intenta superar la negación de los sujetos regionales pero a su vez deja en evidencia la tensión permanente entre acciones diplomáticas/paradiplomáticas que se desenvuelven a distintas

10 La huelga del 21 de diciembre de 1907.

11 Cuando se anunció el cierre definitivo de las salitreras de Tarapacá en la década de los años 1960. 
escalas. Con ello, queda en evidencia la contradicción que enfrenta la diplomacia estatal con las (para)diplomacias regionales. Esta confrontación se da por la formación de identidades diplomáticas en conflicto y el significado distinto que le otorgan al territorio transfronterizo.

\subsection{Algunos aspectos clave} de la diplomacia referidos al caso tarapaqueño: principios constitutivos en pugna y la propuesta de diplomacia como heterología y alteridad.

Un rasgo esencial de la diplomacia estatal-que trataremos de reflejar desde la experiencia chilena hacia Boliviasurge de la tensión constitutiva entre los imperativos para el reconocimiento de diferencias entre Estados soberanos que representan y los imperativos para el acercamiento de los mismos (Bay, 2006). Así es como la diplomacia surgió a causa de la necesidad de comunicarse con otros Estados y llevar a cabo una política exterior hacia ellos (Montobio, 2004). Entonces, el acercamiento que busca entendimiento y posiblemente cooperación con otros Estados podría estar en conflicto con la institucionalización de diferencias y el establecimiento de fronteras fuertes entre los Estados. Sobre todo cuando se requiere de aquellas para consolidar un proyecto de Estado nación en construcción. Por tanto, según Der Derian (1987), el dilema entre diferenciación y acercamiento es el aspecto más funda- mental de la diplomacia. Es así como este autor considera la diplomacia como «la mediación de las relaciones mutuamente alienadas de los Estados» (Der Derian, 1987: 119)

Reconocer esta tensión en torno a las agendas diplomáticas implica que los Estados en ocasiones tenderían a dificultar toda acción exterior emprendida desde las regiones chilenas y bolivianas, excepto cuando las diplomacias estatales se aproximan o acuerdan agendas específicas. Si bien Bolivia y Chile han tenido más años de relaciones diplomáticas que años desprovistos de ella durante el siglo veinte ${ }^{12}$, su complejidad invariablemente ha frustrado intentos de construir proyectos de desarrollo transfronterizo entre las regiones territorialmente contiguas de ambos países, pese a que, por ejemplo, Tarapacá y Oruro han emprendido proyectos de conectividad ininterrumpidamente desde finales del XIX.

Durante el siglo veinte, tomando como hito de inicio el Tratado de 1904, ha habido avances, a saber: las Convenciones sobre Tránsito de 1912 y 1937; en el marco del término de la guerra del Chaco, conflicto en el cual Chile mantuvo una "neutralidad benevolente» hacia Bolivia, se firmaron sendos acuerdos entre los gobiernos

12 Si bien las relaciones diplomáticas han estado interrumpidas desde 1901 a 1904, desde 1962 a 1975 y desde 1978 hasta el año 2000, estos periodos desprovistos de aquella no alcanzaron a sobrepasar los de normalidad: 1904 a 1962 y desde 1975 a 1978. 
de la época, que contribuyeron a la integración económica y favorecieron la integración cultural entre ambos países. Por otro lado, la Declaración de Arica de 1953, los acuerdos de complementación económica de 1955 y el frustrado Abrazo de Charaña. Sin embargo, en 1920 Bolivia presentó por primera vez la demanda ante la Liga de las Naciones para revisar el Tratado de 1904, donde se contemplaba una salida soberana al mar. Más allá de que haya sido promovida, entre otros, por Félix Avelino Aramayo, el negociador boliviano que llevó a su país a la firma del mencionado Tratado de Paz y Amistad con Chile fue, sin duda, la perspectiva "wilsoniana» que se imponía en el campo internacional al término de la Primera Guerra Mundial, la que motivó esa acción unilateral de Bolivia, inaugurando un largo litigio diplomático con Chile por el tema marítimo que perdura hasta nuestros días.

Así, ese marco diplomático, pincelado por el conflicto y las diferencias, ofrece pocos hitos de integración y acuerdo, todos generalmente económicos, entre las dos naciones. Por tanto, es preciso modificar la escala del análisis para encontrar esos episodios donde prime el acercamiento, pese a las diferencias, aunque se hayan frustrado.

Desde la perspectiva del segundo imperativo diplomático señalado más arriba y siguiendo el enfoque crítico propuesto de búsqueda de acercamiento y entendimiento, es posible reivindicar prácticas diplomáticas a distinta escala rastreando expresiones de aquella que operen más allá del arte de gobernar, las que encontramos si fomentamos el conocimiento a partir de una diversidad de fuentes que no estén orientadas a afirmar las certezas soberanas de los Estados y las agendas de prioridad de sus políticas (Constantinou, 2013: 142,143).

En efecto, en el caso del Norte Grande de Chile, por ejemplo, agentes diplomáticos chilenos y bolivianos afincados en las provincias chilenas de Tarapacá, Arica y La Paz, respectivamente (entre 1902 y 1920), buscaban sobre todo mayores facilidades para emprender actividades comerciales y en vista al desarrollo de conexiones transfronterizas, compatibilizar intereses y un mayor entendimiento desde la validación de los parámetros regionales, como la idea de «frontera abierta", en conjunto con los conceptos derivados desde las respectivas capitales, tal como el de «límites fronterizos nacionales»(Castro,2003b:7-8). Por otro lado, los contactos entre las ciudades de Iquique y Oruro entre 1950 y 1960, que alcanzan el clímax a partir de las caravanas de la amistad de 1958 y los contactos diplomáticos a distintos niveles que las promovieron (González, 2012, González y Ovando, 2011), dinamizaron las relaciones diplomáticas oficiales en la denominada "época dorada de las relaciones chileno-bolivianas», a partir de los intentos por consolidar proyectos de desarrollo trasfronterizos (Ovando y González, 2012; González, 2012). 
Desde este enfoque propuesto, identificar cierta trayectoria histórica de la multiplicación de intervenciones subestatales y de la sociedad en el ámbito diplomático y sus lógicas revela su complejidad y pluralidad social, desde la perspectiva de la diplomacia entendida como relaciones de alteridad (De Derian, 1987; Montobio, 2004).

En suma, pese a que por un lado se reconoce un proceso de centralización de la diplomacia hacia actores estrictamente gubernamentales, sobre todo en períodos de mayor conflictividad vecinal, no podemos desconocer la existencia de otros actores sociales presentes en los vínculos entre chilenos y bolivianos, entre ellos las respectivas autoridades regionales -intendentes, delegados presidenciales, empresarios y sindicatos, junto a los comités cívicos que proliferaron en varios hitos clave de las relaciones bilaterales entre los dos países (Castro,2002,2003; González, 2011,2012; González y Ovando,2011). Estos actores representan «...el esfuerzo por encontrar formas de conciliar la existencia de (...) formas de organización social y política tan diversas que se dirían incompatibles entre sí» (Cornago, 2012). Por otro lado, pese a que intentemos rastrear algunos precedentes históricos de la paradiplomacia emprendida entre estos dos países, y así comprender su impacto perdurable y sus lógicas (Cornago, 2012), no podemos subestimar-como hemos dicho al principio someramente- la colisión simbólica entre la diplomacia estatal y la paradiplomacia, puesto que, ade- más de representar a actores diversos, la perspectiva heterológica deja en evidencia la tensión permanente entre estas posibilidades diplomáticas.

\section{Hitos HISTÓRICOS DESDE el TRATAdo DE I9O4 AL CONFLICTO POR LAS AGUAS DEL RÍO LAUCA}

\subsection{Antecedentes}

En la región que nos preocupa, la proliferación de actividades internacionales emprendidas por actores regionales con proyección (para)diplomática partió antes del conflicto del Pacífico de 1879. Estas relaciones transfronterizas marcadas por una cultura, identidad étnica y prácticas comunes en torno a la tradición andina y a los ciclos mineros (salitre, plata, estaño), se remontan a la época colonial, cuestión destacada por varios especialistas que han detectado una resistencia local a los poderes centrales en favor de una articulación regional transandina (Galdames y Ruz, 2010).

Concluido el ciclo de la plata, a mediados del siglo XIX, cuando la economía del salitre todavía no se imponía a la del guano, se registra la primera propuesta de integración física entre el Pacífico y Oruro. Luis Gómez Zubieta la sitúa en 1861, señalando que el 1 de junio de 1864 José Avelino Aramayo, un minero boliviano, lograría un empréstito de la firma inglesa The London County Bankun por un monto de 
1.500.000 libras esterlinas (1998:367). La empresa contratista sería la firma inglesa Petto y Betts, mientras que Hugo Reck, ingeniero alemán, realizó los estudios de factibilidad. Sin embargo, las condiciones impuestas desde los gobiernos centrales impedirían la realización del proyecto y todos los otros que le seguirían hasta que el ferrocarril dejó de ser una alternativa de integración física entre estas regiones contiguas en la década de los años 1930, al surgir el proyecto de un camino internacional.

Las propuestas emprendidas desde las provincias nortinas se habrían extendido a lo largo del siglo XX en forma esporádica y silenciosa, pues algunas regiones epicentro de la Guerra, como Arica, Tarapacá y Oruro, compartieron las mismas preocupaciones en torno a la búsqueda de estrategias de integración para salir de las crisis que las aquejó durante décadas. Por ello, en este apartado desarrollaremos cinco hitos dentro de las relaciones diplomáticas chilenas y bolivianas en torno a Tarapacá que, a nuestro juicio dan cuenta de esta estrategia y, consecuentemente, de las tensiones entre los distintos actores diplomáticos desplegados en torno a aquellos hitos.

Debido a que por razones de espacio no podemos desarrollar todas las fuentes de los hitos referidos, se han escogido algunas que sintetizan mejor los casos.

\subsection{El Tratado de Paz y Amistad de 1904 entre Bolivia y Chile.}

Si bien el Tratado de Paz y Amistad entre Bolivia y Chile de 1904 estableció las fronteras definitivas entre ambos países, ello no significó el término de la porosidad que dichas fronteras tenían durante el ciclo de expansión del salitre. Por el contrario, se acrecentó una dinámica comercial en vista a que dentro de sus prioridades este Tratado contempló facilidades para el libre tránsito del comercio boliviano por territorio chileno ${ }^{13}$. Además de la presión que la economía minera del salitre generaba para obtener mano de obra y bienes de consumo desde Bolivia, se sumaba la demanda de productos industriales de ultramar hacia la minería del estaño en Oruro y hacia otros centros urbanos bolivianos (González 2013). En este marco, los movimientos sociales de Tarapacá (y de Oruro) vieron el espacio intersticial diplomático para plantear las demandas de integración física.

La línea ferroviaria Iquique -Oruro fue una sentida demanda. El 10 de noviembre de 1904 en el periódico La Patria de Iquique ella se expresa con comprensión pero no resignación debido a que no se consideró en el trazado a Tarapacá:

...Grande importancia tiene, pues para nuestro país, este tratado. Sin embargo, los tarapaqueños habríamos

13 El Tratado de Paz y Amistad entre Bolivia y Chile, de 1904, tuvo como compensación principal el ferrocarril entre Arica y La Paz. 
deseado que un ferrocarril hubiese partido desde Iquique. Pero como creemos que no puede prevalecer el interés local sobre el interés de dos naciones, consideramos que deberíamos quedarnos satisfechos con que se lleve a efecto el ferrocarril de Pisagua a Arica, para cuyos estudios presentó proyecto al Senado don Ramón Barros Luco. Si se construyera este ferrocarril, quedaría unido Iquique con el centro de Bolivia. Aunque la línea no fuera directa, quizás, le reportaría grandes beneficios no solo al comercio sino a toda la provincia....

Se sabe que en esa época Ramón Barros Luco formaba parte del directorio de la Compañía FCAB, que competía con Tarapacá por la vinculación con Bolivia. El ramal entre Pisagua y Arica jamás se construyó. De todos modos, el Tratado de 1904 permitió a Bolivia la ansiada articulación ferroviaria con el litoral a través del ferrocarril AricaLa Paz, beneficiando especialmente a sus empresas mineras y agropecuarias. Carmen Gloria Bravo (2008) recuerda las expectativas que generó en empresas mineras como Corocoro que estaban en una difícil situación económica: «a principios de 1913, se comenzó a construir también el ramal a Corocoro y, así, la perspectiva de un ferrocarril administrado por Chile hasta el mineral hizo renacer las esperanzas que la Compañía resolvería definitivamente sus endémicos problemas de transporte» (Bravo y otros, 2008: 63).

En Bolivia, por su parte, la articulación ferroviaria era también una prioridad regional. El periódico La Nación del 23 de noviembre de 1916, hace una referencia a esta red ferroviaria señalando que es un "plan ferroviario que de 10 años a esta parte ha venido desarrollándose en Bolivia». Lo más relevante es su referencia al litoral y la dependencia que esta red tendría con los puertos del norte chileno.

...Nuestros principales centros productores se encuentran ligados a la costa del Pacífico, habiéndose construido ferrocarriles que unan a Bolivia por el norte con el Perú por Mollendo; al oeste con Chile por Arica; al sudeste con el mismo país por Antofagasta; al sur con la Argentina por la Quiaca y al extremo norte le une con el Brasil por el ferrocarril Madera - Mamoré, y a su fin de completar las líneas principales el gobierno nacional se preocupa con verdadera intensidad de construir las siguientes líneas.

Claramente hace referencia a los ferrocarriles de Antofagasta a Bolivia y de Arica a La Paz, pero señala también que «es pues plausible este vigoroso empuje para impulsar y trabajar nuevas líneas ferroviarias...", entre las que se podría considerar el proyecto del ferrocarril de Iquique a Oruro.

Podemos afirmar que el periodo de1864 a 1930 marcó una demanda sostenida que, aunque frustrada, se transformó en un proyecto político transfronterizo, donde la principal palanca de desarrollo supuestamente sería una línea férrea entre Tarapacá y Oruro, integrándose a una red que la comunicaría con Tupiza, La Quiaca, 
Cochabamba, Santa Cruz, La Paz, incluso con Argentina y Brasil, el llamado ferrocarril Panamericano.

La articulación de intereses de las provincias del norte de Chile con Bolivia, queda plenamente clarificada con lo señalado en el diario La Prensa, el 25 de Julio de 1919.

...Ya lo hemos dicho: no conviene a los intereses bolivianos el ingreso del ferrocarril argentino Orán - Yaculba Santa Cruz. Desde el año 72, según lo dice en sus folletos el general Manuel Othon Jofré, el gobierno del Pista hace esfuerzos desesperados para internarse en el corazón de Bolivia, por aquellas regiones ganaderas, agrícolas y (no legible en el texto original).

Como nación fuerte y previsora sabe que no le convendría la competencia, del país extraño, en el desarrollo de los factores económicos que dan vida a los pueblos; que su exportación sería mermada si Bolivia conquistara los mercados europeos y americanos para la colocación de artículos similares a los argentinos.

He ahí la razón de internarse en nuestro territorio para su expansión económica, primero, política, después. Esa es la forma que observan los pueblos fuertes como medio legal de justificar las protestaciones territoriales...

El proyecto de Tarapacá, redactado por Carlos Harms Espejo, también esperaba acceder a las regiones ganaderas, agrícolas y mineras de Bolivia, pero no con un afán competitivo sino complementario, al ofrecer una plataforma exportadora/importadora basada en la experiencia adquirida durante el ciclo de expansión del nitrato.

\subsection{La década dorada de los años 1950}

Como demostración de la dinámica que las acciones diplomáticas generaron en las regiones contiguas chileno-bolivianas, podemos señalar la propuesta surgida al final del gobierno de Gabriel González Videla sobre un posible intercambio de mar por agua, que, como era de esperar, tuvo eco inmediato en la región de Tarapacá. El diario El Tarapacá de Iquique del jueves 17 de agosto de 1950, en su página 5 , señalaba las opiniones del Presidente del Centro para el Progreso de Tarapacá:

Debemos tomar las medidas necesarias para conseguir la diversificación de la economía de la provincia», dijo el presidente Eduardo Zamudio, el actual problema es de vida o muerte para Tarapacá, agregó. Pedir a la representación parlamentaria y a las organizaciones técnicas estatales la obtención de un estudio detallado, sobre el proyecto de irrigación de la pampa del Tamarugal con las aguas de los lagos bolivianos y la construcción de grandes centrales hidroeléctricas para la industria del norte...

También vemos como actores locales condicionaban el destino de la región a este intercambio y vinculaban a otras medidas de desarrollo regional. El primer punto queda detallado en el editorial de El Tarapacá del domingo 6 de agosto de 1950: notas de actualidad lo que cuenta, el interés nacional:

(...) La más importante de ellas sería el uso de las aguas de algunos 
lagos bolivianos como el Titicaca, en un plan de regadío de la Pampa del Tamarugal y los valles ariqueños y en una fuente de energía eléctrica de bajísimo costo para aprovecharla en la industria salitrera y en la creación de nuevas fuentes de actividad. (...) En la provincia de Tarapacá ha habido dos reacciones bien distintas frente a tan trascendental asunto. Mientras en Iquique el proyecto es considerado como la única posibilidad fundamentada para transformar la vida económica del departamento dándole un vigor permanente e ilimitado, en Arica se le combate con desusada obstinación e intransigencia, asegurando que será un golpe de muerte para ese departamento, y tachando de antipatriótica la idea la idea de la sesión de una franja del territorio a Bolivia.

Cabe destacar las visiones contradictorias entre ambas ciudades y la negativa, ariqueña apelando al nacionalismo.

En cuanto al condicionamiento a la cesión de territorio, el abogado iquiqueño Guillermo Bonilla Bradanovich, miembro del Comité para el Progreso de Tarapacá, en entrevista realizada el 17 de agosto en el diario El Tarapacá, en su página 5 señala enfáticamente su apoyo a la entrega de un territorio para Bolivia a cambio de beneficios para la región, algo inédito en la actualidad:

$¿$ Considera usted conveniente la sesión del corredor?

$* *$ Considero que Bolivia debe tener una salida al mar. En realidad el mar es la vía que más acerca a los pueblos y fomenta su desarrollo espiritual y económico. Bolivia se encuentra actualmente sometida a un aislamiento relativo. Sin embargo, no debe perderse de vista que hasta el momento se le ha cargado la mano solo a Chile indicando que es el país que tiene que desmembrarse para que el altiplano tenga acceso al pacífico. Debemos conceder que otros países tienen igual obligación si es que esto podría denominarse así. Chile al remover la necesidad de la salida al mar lo hace desde el punto de vista de los conceptos modernos de derecho internacional que se basan en la justicia y la equidad.

«Desde el punto de vista de Arica, ¿Esto será beneficioso?

** Según mi modo de pensar, considero que la sesión de un corredor a Bolivia en la forma que se ha anunciado por la prensa y declaraciones de nuestra cancillería, Arica se beneficiaría con una salida al mar de Bolivia, siempre que fuera declarado puerto libre.

$¿ Y$ para el porvenir de la provincia de Tarapacá?

**A Al contar nuestra provincia con un gran centro comercial y económico como sería la categoría de nuevo puerto boliviano, las posibilidades económicas, comerciales y turísticas tendrían para nosotros una gran importancia. Contando con agua en abundancia, traída desde los lagos del territorio boliviano se abrirían para el futuro de tarapacá posibilidades insospechadas para su bienestar económico y la quimera de la agricultura y electrificación pasarían a ser una realidad.

Hemos definido la década de los años 1950 como «dorada» en las relaciones bilaterales entre Bolivia y Chile (Ovando y González 2011), en que se firmó un Tratado de Complementación Económica el 31 de enero de 1955, se generaron importantes demandas de in- 
tegración económica entre las regiones de Tarapacá (que incluye a la antigua provincia de Arica) y Bolivia, siendo el oleoducto de Sica Sica el producto más concreto que quedó como resultado de tanto esfuerzo paradiplomático y diplomático durante ese período. Sin embargo, este oleoducto - que permite a Bolivia la exportación de crudo hacia Estados Unidos ${ }^{14}$, y que recorre 595 kilómetros, es casi ignorado por la población regional. El oleoducto Sica Sica fue resultado de las negociaciones entre los gobiernos de Carlos Ibáñez del Campo y Víctor Paz Estenssoro, pero fue construido en la década siguiente, específicamente en 1965.

La apertura que implicó esta buena relación diplomática entre Bolivia y Chile durante los gobiernos de Carlos Ibáñez del Campo y Víctor Paz Estenssoro impulsó a los movimientos regionales de Oruro y Tarapacá a reponer la vieja idea de una integración física transandina. Efectivamente, en enero de 1955 el presidente boliviano visitaría Chile y el chileno Bolivia en el mes de agosto de ese año. Carlos Bustos afirma al respecto: «la única visita oficial efectuada a ese país por un Presidente de Chile en casi dos siglos de historia republicana» (2004:184), agregando que «los años posteriores fueron de entendimiento y cooperación entre Chile y Bolivia». Durante esos años de «entendimiento y cooperación» surgie-

14 La Compañía minera Golf Oil en 1965 construyó este oleoducto desde Santa Cruz de la Sierra hasta el puerto chileno de Arica. ron las caravanas de la amistad entre Oruro y Tarapacá.

\subsubsection{Las caravanas de la amistad de 1958 entre Oruro y Tarapacá}

Situamos las caravanas de la amistad o de la integración, términos que se utilizaron en la época, dentro de «década dorada» de las relaciones diplomáticas entre Bolivia y Chile. Ellas fueron la expresión paradiplomática regional de ese momento de acercamiento entre ambos países y, por lo mismo, la ventana de oportunidad para Oruro y Tarapacá de volver a insistir en el proyecto de integración física.

Las caravanas se iniciaron el 20 de mayo de 1958 cuando los orureños cruzaron la cordillera para llegar a Iquique el simbólico 21 de mayo, fecha que para los iquiqueños tiene un valor fundacional. Del mismo modo, los tarapaqueños lo hacen en invierno, llegando el 5 de agosto, un día antes de las fiestas patrias de Bolivia. Las esperanzas reflejadas en los discursos en Iquique y en Oruro, tenían como telón de fondo un justificado temor de que la diplomacia oficial cambiara de rumbo.

La información publicada el miércoles 15 de enero de 1958 en el diario El Tarapacá de Iquique, extraída días antes del diario La Patria de Oruro, probablemente refleja la importancia que para los pobladores de estas regiones significaba el camino internacional y su reivindicación en tanto expresión diplomática recogida de fuentes no tradicionales. La noticia señalaba que: 
Veinte mil campesinos bolivianos ofrecieron al gobierno de su país trabajar en la construcción del camino Iquique a Oruro. El ofrecimiento fue hecho a través de las autoridades de Toledo, Pueblo del Departamento de Oruro, directamente al Presidente de la República de Bolivia, doctor Hernán Siles. Toledo, es uno de los pueblos por dónde pasará el trazado definitivo que unirá a Iquique y a Oruro, al construirse éste por la vía de Chusmiza en Chile. El pueblo vive de la agricultura, pequeña ganadería, existe una actividad industrial textil casera y que tiene una amplia zona de atracción minera.

El periódico orureño La Patria, tituló el miércoles 21 de mayo: «La Caravana cumplió sin novedad su última etapa. A las 13:15 comenzaron a llegar los primeros carros a Iquique, donde el pueblo les recibió con singular entusiasmo al son de la diablada. Ningún carro se detuvo en el camino ni sufrió demora». Mientras el periódico El Tarapacá de Iquique del mismo día señaló en su página 3: «Un afectuoso recibimiento tributó Iquique a la caravana de la amistad».

Las comunidades de Iquique y Oruro coincidieron en el mismo proyecto, que no era contrario a la razón de Estado y menos a la unidad nacional, solamente pretendían tener una alternativa de desarrollo compartido aproximando sus economías. Esta acción fue (para) diplomática y pudo haber sido una alternativa para resolver los litigios entre ambos países a partir de 1919 .

El Tarapacá de Iquique es más expresivo al relatar el paso de la caravana orureña por las calles del puerto:
En su paso por estas calles la ciudadanía de Iquique volvió a exteriorizar su aprecio y admiración y simpatía a los esforzados pioneros de una ruta que abre esperadas posibilidades para el intercambio amplio de las ciudades de Iquique y Oruro. Los gritos de «jviva Bolivia!», «jviva Iquique!», « ¡viva el camino de Iquique a Oruro!» se fueron repitiendo con una continuidad tal que no tiene parangón y que es la fiel expresión de los habitantes de dos pueblos que necesitan unir sus destinos comerciales culturales y sociales, a través de ese verdadero cordón umbilical que sería el camino definitivo entre las dos ciudades...

No fue menor la expresión de afecto que recibieron los tarapaqueños cuando llegaron a Oruro en la víspera del día nacional de Bolivia. El cronista iquiqueño Luis Díaz Salinas, uno de los protagonistas de esta caravana, relata en su libro Sendas de nostalgias, la llegada a Oruro: «La entrada a la ciudad fue apoteósica. Dos enormes locomotoras formaban un arco de triunfo, demostrando el afecto de los obreros y empleados ferroviarios, y simbolizando la derrota de las odiosidades alimentadas por tantos años de desconfianza mutua. Al ver el ingreso de los vehículos, algunos hombres lloraban de emoción, muchos de los cuales habían trabajado en las oficinas salitreras de Tarapacá, y después de largos años volvían a ver rostros de hermanos chilenos» (1992: 282).

La Patria del domingo 10 de agosto de 1958 calificó de «intenso el intercambio artístico» entre ambos pueblos. La estudiantina 10 de febrero realizó 
presentaciones «utilizando los micrófonos de Radio El Cóndor». El día 6 de agosto hizo una gala en el paraninfo universitario en honor de los visitantes. Ese mismo día el conocido grupo Sajama realizó en dos oportunidades "un viaje musical por las regiones de la patria» a las ocho horas en Radio Universidad y a mediodía en la emisora ferroviaria. Esta segunda presentación del conjunto Sajama fue dirigida a los componentes de la Caravana, a cuyo efecto el director artístico de la institución actuante, Flores Barrientos, pronunció un discurso de ofrecimiento en cuyas partes salientes expresó:

Habéis ascendido sin desmayos la cordillera y os habéis hecho azotar con las ventiscas de la altipampa y como jamás en la historia de los pueblos, se ha producido un nuevo tipo de invasión de territorios ajenos: en son de paz, de amor humano y de comprensión, sin el malévolo recurso de las armas. Y en el momento culminante de una de común. Oruro e Iquique se sirven de un mismo plato, el que contiene el manjar de la buena voluntad, fruto apetecido, pero nunca tan bien logrado como en las memorables ocasiones de mayo y agosto...

Del mismo modo, una síntesis de lo que fueron los antecedentes de la iniciativa de realizar las caravanas de la amistad para presionar por el camino internacional Iquique-Oruro, nos la entrega el diputado por Iquique, Juan Checura Jeria, en una crónica en el diario El Tarapacá del 18 de febrero de 1958, página 4, a saber:
En el periodo parlamentario pasado se impulsó a través del Congreso la realización de esta obra, consultándose recursos legales por iniciativa parlamentaria para no dejar ni un solo blanco a las evasivas del Ejecutivo. Luego, en los primeros días de 1955, se planteó el problema en La Paz ante nuestro Embajador y las autoridades viales bolivianas. Como parlamentario de la época me correspondió impulsar esta obra y viajar acompañado del Director de Vialidad de Chile, señor Eduardo Paredes, a Bolivia.

Esas conversaciones fueron previas a la inclusión de la obra en el Convenio Internacional suscrito después en Arica por los presidentes Ibáñez y Paz Estenssoro. Con esto quedaba el problema rubricado como un compromiso internacional que no puede ni debe desconocerse por ningún de los dos países, y sobre esta base han continuado las gestiones para que se cumpla el requisito previo de fijar la ruta definitiva que llevará la vía internacional, ya que no es posible que los fondos que está produciendo Chile por iniciativa parlamentaria, se estén invirtiendo en soluciones transitorias que no son las más adecuadas y se siga dilatando la realización de una obra que es vital para el entonamiento económico de Tarapacá.

Sin embargo, este "compromiso internacional» fue lamentablemente desconocido por las autoridades de ambos países. Mientras recorrían las calles de Iquique los camiones que partieron hacia Bolivia, los participantes pudieron ver la propaganda electoral de ese año el nombre de Jorge Alessandri Rodríguez, el próximo gobernante chileno. Durante su mandato surgirá el conflicto 
por las aguas del río Lauca que distanció a los dos Estados nacionales y cerró las puertas a la integración subregional. En palabras del ya citado diputado por Tarapacá, Juan Checura Jeria: «es preciso seguir golpeando la conciencia no solo de nuestros gobernantes y parlamentarios, sino que también la de nuestros propios dirigentes locales para evitar que en definitiva quede diferida una obra que durante muchos años ocupó la atención preferente de los ciudadanos y que llegó a cristalizarse en una realidad internacional en su etapa inicial y que por parte de Chile quedó incluso comenzada en sus estudios y construcción, ya que el camino de Iquique a Oruro logró imponerse después de largos años de perseverante labor. Lamentablemente este Gobierno, tal como hizo con la fábrica de cenizas de soda, ha resuelto la paralización de los trabajos argumentando, entre otras cosas, su «injustificación económica» » (El Tarapacá, viernes 2 de septiembre de 1960).

\subsection{La Junta de Adelanto y el Plan Andino}

La década dorada de los años 1950 en las relaciones diplomáticas entre Bolivia y Chile enmarcadas dentro de esta estrategia desarrollista estatal no solo habría de provocar las caravanas de la amistad, que dejaron en la memoria regional, tanto en Oruro como en Tarapacá un capital simbólico sobre la integración, sino también un producto bien concreto como fue el oleoducto de
Sica Sica. En Arica, además, posibilitó que se creara el régimen del Puerto Libre de Arica, por medio del Decreto con Fuerza de Ley $N^{\circ}$ 303, que transformó a este puerto en una plataforma comercial para la región y el sur del Perú y el occidente de Bolivia.

Mientras en Iquique se luchaba por llegar a Oruro con las caravanas de la amistad, en Arica una nueva normativa (Ley $\mathrm{N}^{\circ} 13.039$ ) definiría lo que se conocerá como la palanca de desarrollo regional más importante de la historia de esta provincia: la Junta de Adelanto (J.A.A.), que sentaría las bases para la experimentación de un "polo de crecimiento» expresado en un barrio industrial. Mientras, la J.A.A. apoyaba inversiones para transformar la ciudad en un entorno adecuado para el desarrollo industrial, como la construcción de un aeropuerto, una hostería, una universidad, un estadio de fútbol, etc. Según Luis Galdames: «El éxito pareció haber llegado a Arica para quedarse. En el imaginario popular se piensa que la manifestación más explícita del éxito del puerto libre lo constituyó el aumento de población. Según el INE, el censo de 1952 arrojó para Arica una población de 23.033 almas» (Galdames, 2005:12). La ciudad que no había gozado de los beneficios de la economía salitrera y sufrido las consecuencias del litigio diplomático entre Perú y Chile entre 1884 y 1929 , parecía que por fin tenía la oportunidad de volver a tener la importancia que tuvo durante la Colonia, cuando era el puerto de Potosí. 
A poco andar de su gobierno, Jorge Alessandri Rodríguez modificó la Ley de la Junta de Adelanto de Arica, que ha sido considerada por la población ariqueña como la organización más eficiente en la historia de la provincia, pues tenía «autonomía en lo que decía relación con el patrimonio, los presupuestos y las decisiones, pretendía erigirse en el modo más válido de regionalización, favoreciendo el desarrollo de la industria y convirtiéndose en el motor de la inversión pública» (Galdames et al 2010:258).

El Presidente Alessandri había revisado el problema regional desde el momento en que asumió el Gobierno. Los diputados por Tarapacá Juan Luis Maurás y Raúl Hernán Brücher, se habían entrevistado con él para plantearle las viejas reivindicaciones regionales.

A partir de entonces la ciudad de Arica iniciaría un período de expansión económica, que se extendería por un par de décadas y que no volverá a conocer hasta la actualidad. Por lo mismo, en la percepción de la población sigue persistiendo como el periodo dorado de la historia reciente de la provincia. Curiosamente, como veremos más adelante, el conflicto por las aguas del río Lauca coincide con ese período, por lo que cabe preguntarse si no afectó el crecimiento de Arica, basado en una plataforma portuaria de importaciones y exportaciones (que incluía a Bolivia) a través de un puerto libre unido a un barrio industrial con subsidio estatal o si, simplemente el polo de crecimiento funcionó sustentado en el mercado regional y nacional, prescindiendo de Bolivia.

También cabe preguntarse si el «conflicto del Lauca» significó para esta provincia el término de una mirada transfronteriza del desarrollo regional, concentrándose en la demanda del mercado nacional hacia su producción industrial y sus importaciones a través del puerto libre o en otras palabras, si se impuso el desarrollismo estatal a la mirada transfronteriza del desarrollo regional ariqueño. La Enciclopedia de Arica, editada en 1972, señala con toda claridad que:

La Junta de Adelanto de Arica, desde su creación, ha estado sosteniendo el significado macizo de su ubicación geográfica, de sus áreas de influencia, y la necesidad de su aprovechamiento para beneficios regional y nacional. La firma del Pacto Andino le da ahora valor formal a tal pragmatismo.

Arica es la puerta de salida de una vasta región de la cuenca interior de América Latina. Lo fue desde la época de la Colonia, cuando la plata de los Lípez se embarcaba por Arica y cuando el azogue para su tratamiento se descargaba en ella.

Lo es desde que el F.C. de Arica a La Paz, en su época, era la vía más corta del Pacífico a Bolivia. Lo es, ahora, con la próxima terminación del camino internacional de Arica a la frontera boliviana. Lo es también por la integración cotidiana y forzada con el Depto. de Tacna, establecida por el Tratado de 1929 con el Perú. Lo es con el oleoducto Sica Sica / Arica, que permite el embarque de petróleo del oriente boliviano por el Pacífico. Lo será por la extensión de la red cami- 
nera y ferroviaria de Bolivia a Santos (Brasil), por Corumbá. (Enciclopedias regionales 1972:82).

Esta perspectiva no es ajena a la discusión ideológica - desarrollista- de los primeros años de la década de 1970 , del que fue expresión el Plan Andino. Algunos intelectuales y académicos se sintieron llamados a participar en este proyecto político de desarrollo transfronterizo: especialmente John Murra tendrá influencia intelectual entre sus pares de la Universidad del Norte y en la propia Junta de Adelanto de Arica (Galdames y Ruz 2010), debido a su innovador enfoque de interpretación de la economía andina. La discusión teórica sobre el desarrollo, donde "lo andino" comenzaba a ocupar un espacio relevante en estas regiones y también en el marco político e ideológico de la época.

En Iquique también se desarrolló el Plan Andino a cargo del geógrafo Freddy Taberna, quien apoyado por especialistas, entre los cuales se encontraba el arqueólogo Lautaro Núñez, inició un estudio sobre el altiplano de Tarapacá y sus relaciones transfronterizas. Coincidentemente, llega a la alcaldía de esta ciudad un joven socialista, Jorge Soria Quiroga, quien hace propia la tradición regional de integración física con Oruro, proyectándola hacia el continente a través de los corredores bioceánicos. Una nota escrita por el periodista local Rodolfo Valencia en El Tarapacá del martes $1^{\circ}$ julio de 2008, recoge en gran medida esta visión de Soria:
Con el objetivo de hacer entrega de una carta dirigida a la presidenta Michelle Bachelet, Jorge Soria Quiroga, acompañado de su hijo Jorge Soria Macchiavello, Consejero Regional, llegaron en una sorpresiva visita en la tarde de ayer hasta el gabinete del intendente Pablo Valenzuela.

En el documento Soria hace mención que la presidenta con su firme y decidida voluntad de concretar la obra de construcción de la ruta Huara- Colchane durante su mandato, está haciendo realidad los anhelos de miles de generaciones de iquiqueños, que por largos años han luchado por esta vía, «que nos integra con el corazón de Sudamérica a través de los corredores bioceánicos, anhelo al cual he dedicado toda mi vida, y que por lo mismo no puedo sino expresar mi máxima satisfacción.

Además, el inhabilitado alcalde hizo referencia que «había perdido la fe debido a promesas no cumplidas, desengaños y desilusiones, en una petición que considero muy justa, y de tanta importancia para el desarrollo de Iquique, el norte de Chile, y los países hermanos que conforman el corazón de Sudamérica. Pero Ud. señora presidenta nos la ha devuelto, y nos ha hecho creer de nuevo que existen políticos que luchan por algo más que llegar al poder. Esas mujeres y hombres que buscan el ejercicio de la vida pública para satisfacer las reales necesidades de los pueblos. Por ello acepte que su estatura de gran líder política, quede grabada en la memoria histórica y los corazones de los iquiqueños» planteó.

Es notoria la similitud entre las palabras del diputado iquiqueño Juan Checura Jeria, en El Tarapacá, del viernes 2 de septiembre de 1960, cuando 
criticaba el fracaso de las caravanas de la amistad, con las de Jorge Soria.

\subsubsection{El conflicto por las aguas del río Lauca.}

Concluida la década de los años 1950 , se inicia la siguiente con el Gobierno de Jorge Alessandri Rodríguez, período conflictivo que llevará a la ruptura de relaciones diplomáticas entre Bolivia y Chile, donde las aguas del río Lauca fueron, al parecer, un factor concomitante de una causa más profundas de las relaciones entre ambos Estados nacionales, que no es otro que el acceso soberano de Bolivia al océano Pacífico. Posiblemente el problema del Lauca, como la más reciente controversia por las aguas del río Silala, si hubiese sido entre otros países, podría calificarse de baja intensidad, pero para el caso de Bolivia y Chile alcanza de inmediato caracteres de una controversia internacional. Sin embargo, como afirma Carlos Bustos «la llamada «cuestión marítima» comenzaba a agitarse conjuntamente con las acciones relacionadas con las obras del río Lauca y a entremezclarse más y más ambos temas» (2003:162).

Chile realizó obras para aprovechar aproximadamente la cuarta parte del área colectora ubicada en territorio chileno, reconociéndose que existen « 21 afluentes en total en territorio chileno que acrecientan el caudal del río Lauca» (Memoria del Ministerio de Relaciones Exteriores 1963:3). Al margen de que las aguas de este río, que nace en Chile, terminan absorbiéndose o evaporándose en el salar boliviano de Coipasa, existe un derecho que rige los ríos de curso internacional. Sin perjuicio de lo anterior, la acusación boliviana ante la OEA de una agresión por parte de Chile a su soberanía debido a las obras de regadío que beneficiaban a agricultores andinos utilizando el margen chileno del río Lauca, parecía sin duda una exageración diplomática, que apelaba a una imagen del territorio normalizadora y monopolizadora del espacio (Nuñez, et al, 2013) desconociendo las practicas andinas transfronterizas y sus propias imágenes. Bolivia rompió las relaciones diplomáticas oficiales con Chile el 15 de abril de 1962, al no paralizar este las obras de regadío. Lo anterior necesariamente transformó un litigio jurídico en uno político, afectando a las regiones contiguas de Bolivia y Chile, Oruro y Arica-Parinacota, respectivamente, junto con sus demandas por un desarrollo transfronterizo.

Pese a que el litigio por las aguas del río Lauca llegó a estar a un mismo nivel en el discurso político boliviano en los foros internacionales que la reivindicación marítima, aunque este era considerado como «el problema mayor», Bolivia abandonó "paulatinamente a los pocos años toda referencia al Lauca» (Figueroa 1992:79). Ello demuestra que (posiblemente sea el mismo caso del Silala) en realidad haya sido solo un «factor concomitante». Tanto es así, que el problema del Lauca quedó fuera de la Agenda de los 13 
puntos establecida por los gobiernos de Morales y Bachelet.

Aquí sostenemos que, en rigor, la reivindicación boliviana por el supuesto uso chileno ilegal de las aguas de los ríos Lauca, Caquena y Silala, no tiene un objetivo en sí mismo sino que se enmarca en la reivindicación marítima de ese país. Un ejemplo es la crítica del ex diplomático y economista boliviano Andrés Guzmán Escobari, en el periódico digital El Muro Nacional el 18 de junio de 2013, sobre el uso de las aguas bolivianas. Más allá de los argumentos históricos y técnicos que Guzmán Escobari expone, aquí lo que interesa es el párrafo con el que concluye su artículo:

Además, teniendo en cuenta que Chile y Bolivia se encuentran definiendo la más difícil y prolongada de sus controversias en el ámbito jurisdiccional; es muy importante que ambos gobiernos preparen en cuanto sea posible el ambiente para afrontar el resultado de ese proceso judicial y para ello, la resolución de los temas pendientes entre ambos países, es sin duda y lógicamente, lo primero que se debería hacer. En ese sentido, es importante promover el diálogo que permita alcanzar acuerdos para garantizar el abastecimiento hídrico del norte chileno y el resarcimiento y contraprestación correspondientes para Bolivia.

En otras palabras, el mismo actor diplomático y reivindicacionista, puede transformarse en actor paradiplomático e integracionista, cuando se aborda el problema a escala transfronteriza y regional y en la propia singularidad de la representación del espacio.

\section{CONClusiones}

Intentamos problematizar las relaciones diplomáticas chilenas hacia Bolivia buscando interpretarlas a partir de estas nuevas aproximaciones críticas, que se enfatizan en la pluralidad de expresiones -en torno a las regiones de Tarapacá y Oruro- buscando superar el extrañamiento entre las sociedades, particularmente la chilena y boliviana distanciadas por una guerra.

Consideramos que el histórico problema del desarrollo de Tarapacá y su posibilidad de superarlo a través de un proyecto regional transfronterizo, en vista a las regiones bolivianas, puede abordarse tanto desde las prácticas paradiplomáticas locales como desde las instituciones del gobierno central, llegando a una agenda compartida pero no exenta de limitaciones.

En relación con estas dos agendas ubicadas a distinta escala, vimos que se expresan acuerdos puntuales originados en demandas regionales a propósito de negociaciones entre las diplomacias de Chile y Bolivia, a partir de su aspiración de conformar un proyecto regional de carácter transfronterizo que suele chocar con los cálculos del centro.

No cabe duda que hubo un momento crítico en que las expresiones paradiplomáticas de las regiones contiguas de Bolivia y Chile entraron en colisión con la diplomacia tradicional. Nos refe- 
rimos a la primera década del siglo XX, momento en que los Estados-nacionales desechaban la integración territorial a través de líneas férreas entre Iquique y Oruro pese a que ambas continuaron insistiendo en su factibilidad o reemplazaron la demanda por carreteras en las décadas siguientes. Podemos sostener que este hito se repite constantemente con distintos énfasis durante buena parte del siglo XX.

Este juego diplomático a escala múltiple debe interpretarse teniendo en cuenta las formas de pensamiento y conocimiento que se emplean al gobernar (Museta, 2009), sobre todo desde las diplomacias oficiales. En especial se trata de un tipo de Estado que ideológicamente responde a las demandas regionales internacionales orientado, primero, por una elite económica minera (fines del XIX), que coincide con la diplomacia de posguerra del Pacífico, estimulando la integración económica a escala regional en el marco del Ciclo del Salitre. Seguidamente, por un Estado guiado por el desarrollismo y las aprensiones geopolíticas de posguerra y su corolario, el control vertical de las regiones. A partir de estas premisas, el centro en ocasiones tolera estas iniciativas y en otras niega los intentos más originales de apertura diplomática que rebasen del arte de gobernar y busquen el entendimiento con las regiones bolivianas, guiado por la alteridad y la continuidad territorial.

Con todo, siguiendo a Constantinou y Der Derian (2010), destacamos que hacia 1950 las expresiones paradi- plomáticas presentes en Tarapacá en torno a las Caravanas de la Amistad y en Arica en torno al Plan Andino y la J.A.A, pese a experimentar con expresiones que permitan ensayar la reconciliación de formas rivales de existencia, van quedando subsumidas o tienden a depender de las estratagemas de la diplomacia estatal, que apuestan por la mera defensa de los intereses autodefinidos como nacionales.

En efecto, dicho Estado encara la política salitrera permitiendo la movilidad fronteriza. Ya en el siglo XX responde al problema del desarrollo tarapaqueño recepcionando la demanda por la ruta Iquique-Oruro impulsada por las caravanas, pero desechada, una vez que surgen problemas diplomáticos que atentan contra el interés nacional, apelando a «injustificación económica». Seguidamente, estas regiones ponen en marcha la J.A.A y el Plan Andino, pero bajo la sombra del conflicto del Lauca y bajo el prisma de miradas del desarrollo contradictorias: el desarrollismo estatal más atento a la industrialización y al mercado regional y una mirada regionalista innovadora de la integración andina impulsada, entre otros, por John Murra.

Por otro lado, si bien en los hitos mencionados queda en evidencia el grado de complementariedad que alcanzaron a articular actores regionales y nacionales cuando se trataba de proyectos específicos, sobre todo teniendo la idea de un proyecto regional de desarrollo transfronterizo, no podemos subestimar la perdurable colisión sim- 
bólica surgida entre la diplomacia y la paradiplomacia.

Finalmente, la constatación de que desde siempre ha existido un espacio (en torno a Tarapacá y Oruro) que expone continuidades territoriales y culturales en torno a las dinámicas paradiplomáticas entre Chile y Bolivia, y que no se corresponde con la soberanía territorial de cada Estado. Por otra parte, la diplomacia se ha caracterizado por enfatizar las discontinuidades, donde el otro, el extranjero, el forastero, es la discontinuidad por antonomasia.

La continuidad, en cambio, ha sido una realidad histórica que ha marcado las demandas regionales de desarrollo, no obstante los respectivos Estados. Así, queda en evidencia la contradicción que enfrenta la diplomacia estatal con las (para)diplomacias regionales. Esta confrontación se da por la formación de identidades diplomáticas en conflicto y el significado distinto que le otorgan al territorio transfronterizo: el Estado chileno y el boliviano representan una escala normalizadora en torno al límite y lo nacional, y las regiones, un territorio transfronterizo y la multiterritorialidad (Nuñez, y otros, 2013).

Finalmente, reconocemos la dificultad - sobre todo asociada a un posible voluntarismo regionalista - de abordar experiencias paradiplomáticas en retrospectiva. Porque es más asequible centrarse en las expresiones manifiestas de este fenómeno como resultado de la globalización actual y no en expresiones latentes de este mismo fenómeno, que debemos abordar y develar yendo al pasado, rescatando la singularidad y subjetividad de estos fenómenos silenciados por la escala nacional. Sin embargo, en Tarapacá es posible identificar, detrás de los fracasos o frustraciones, una histórica conducta integracionista transfronteriza regional que, sin desconocer ni rechazar las diferencias y litigios entre Bolivia y Chile, se aproximan más a una continuidad paradiplomática que a una discontinuidad diplomática.

\section{Bibliografía}

Anaya, Ricardo (1987) «Arica Trinacional», La Paz Editorial Los Amigos del Libro.

Aranda, Gilberto; Cristian Ovando y Alejandro Corder. «Experiencias paradiplomáticas en la región de Tarapacá y su proyección subregional», Estudios Internacionales $\mathrm{N}^{\circ} 165$, pp. 33-74.

Bay, Steffen (2006) «La diplomacia possoberana de red de la UE hacia sus vecinos del Este. Hacia un nuevo concepto de diplomacia» Trabajos y ensayos $\mathrm{N}^{\circ} 4$, enero Departamento de Derecho Internacional Público, Relaciones Internacionales e Historia del Derecho Universidad del País Vasco, pp. 4-20.

Boisier, Sergio (2004) «Desarrollo territorial y descentralización. El desarrollo en el lugar y en las manos de la gente». Revista EURE, Vol. XXX, $\mathrm{N}^{\circ}$ 90, pp. 27-40, septiembre.

Bravo, Carmen y otros (2008) El mineral de Caracoles. Arqueología e historia de un distrito minero de la región de Antofagasta (1870-1989). Santiago: Consejo Nacional de la Cultura y las Artes.

Bustos, Carlos (2004), Chile y Bolivia. Un largo camino. De la independencia a Monterrey, Santiago: RIL Editores.

Castro, Luis (2003b) «Un chileno en La Paz, varios bolivianos en Iquique: Ideas y visio- 
nes sobre la integración económica y las relaciones políticas entre Arica, Tarapacá y Bolivia (1903-1920)». Revista de Ciencias Sociales, $\mathrm{n}^{\circ} 13$, pp. 4-12.

Castro, Luis (2002) «El temprano regionalismo de los tarapaqueños durante el ciclo salitrero: de los discursos económicos a la identidad socio-cultural, 1880-1930». Revista de Ciencias Sociales, $\mathrm{n}^{\circ} 12$, pp.19-27.

Castro, Luis (2005) Regionalismo y desarrollo regional: debate público, proyectos económicos y actores locales (Tarapacá 18801930). Viña del Mar: CEIP Ediciones.

Castro, Luis (2003) «Espejismos en el desierto: proyectos ferroviarios e integración subregional (Tarapacá 1864-1937)». Si somos americanos, Revista de estudios transfronterizos, Vol. V: Año 4: 21-48.

Colacrai, Miriam y Maria Elena Lorenzini (2005) «La política exterior de Chile: ¿excepcionalidad o continuidad? Una lectura combinada de «fuerzas profundas» y tendencias». Confines 1/2: 45-63.

Constantinou, Costas (2013) «Between Statecraft and Humanism: Diplomacy and Forms of Knowledge, International Studies Review n ${ }^{\circ} 15$, pp. 141-162

Constantinou, Costas y Der Derian, James (2010) Sustainable diplomacies. Londres: Palgrave.

Cornago, Noé (2013) Plural Diplomacies: Normative Predicaments and Functional Imperatives. Amsterdam: Martinus Nijhoff Publishers.

Cornago Noé (2013b). «Diplomacy decentralized: subnational politics and the making of sustainable diplomatic couples in Latin America», Brigitte Vassort-Rousset(ed): Building Sustainable International Couples: Critical Components of a Strategy Towards Peaceful and Constructive Cooperation. Basingstoke: Palgrave.

Cornago, Noé (2009) «La diplomacia como heterología».Universidad del País Vasco, Leioa (manuscrito ).

Couyoumdjian, Juan (1986) Chile y Gran Bretaña. Durante la Primera Guerra Mundial y la Post-Guerra, 1914-1921. Santiago, de Chile: Editorial Andrés Bello - Pontificia Universidad Católica.
Der Derian, Jean (1987), On Diplomacy: A Genealogy of Western Estrangement. Oxford: Blackwell.

Díaz Salinas, Luis (1992). Sendas de nostalgia. Iquique, recuerdos de un siglo inquieto. Iquique: Delaire y Cárdenas Editores.

Editorial de Enciclopedias Regionales (1972), «Ensayo de información general del departamento de Arica», Enciclopedia de Arica, Santiago, auspicio de la Universidad de Chile.

Escobari Cusicanqui, Jorge (1979). Historia Diplomática de Bolivia. La Paz: Talleres Industrial Gráfica.

Figueroa, Uldaricio (1992) La demanda marítima boliviana en los foros internacionales, Santiago de Chile: Editorial Andrés Bello.

Eyzaguirre, Jaime (1963). Chile y Bolivia, esquema de un proceso diplomático. Santiago de Chile: Zig-Zag.

Fermandois, Joaquín (2005), Mundo y fin de mundo: Chile en la politica mundial 19002004, Santiago: Ediciones Universidad Católica de Chile.

Galdames, Luis y Rodrigo Ruz (2010) «La Junta de Adelanto de Arica y John V. Murra. Dos lecturas sobre el desarrollo andino en el norte de Chile», Chungará, Revista de antropología chilena, vol. 42, $\mathrm{n}^{\mathrm{o}} 1$, pp. 257-270.

Galdames, Luis (2005) «El discurso del Estado a través de la creación del puerto libre de Arica: Aproximación semiológica", Diálogo Andino, $\mathrm{n}^{\circ}$ 26, pp. 9-14.

Galtung, Johan (1995), Investigaciones teóricas. Sociedad y cultura contemporáneas. Madrid: Editorial Tecnos.

Gavira, María Concepción (2005) Producción de plata en el mineral de San Agustín de Huantajaya (Chile), 1750-1804. Chungará, vol. 37, n 1, pp. 37-57.

Gómez, Luis (1998), Ferrocarriles en Bolivia del anbelo a la frustración 1860-1929. La Paz: UMSA.

González, Sergio (2011) Las históricas relaciones entre Tarapacá y Oruro: la frustrada tentativa de integración transfronteriza durante el ciclo de expansión del salitre 
(1864-1928), Revista de Geografía Norte Grande, n50, pp.63-85.

González, Sergio. (2012). Sísifo en los Andes. La (frustrada) integración física entre Tarapacá y Oruro: las caravanas de la amistad de 1958. Santiago de Chile: RIL.

González Miranda, Sergio (2004) La tercería boliviana y el problema de la mediterraneidad, Revista Fuerzas Armadas $y$ Sociedad, Año 18, no 1 y 2, pp. 23-36.

González Miranda, Sergio (2013) «¿Espacio o territorio? La integración transfronteriza de la economía salitrera. El caso de Bolivia (1870-1920)». En: Fronteras en Movimiento e imaginarios geográficos. La cordillera de Los Andes como espacialidad sociocultural, Andrés Núñez, Rafael Sánchez y Federico Arenas (eds). Santiago, RIL Editores, pp. 275-305.

González, Sergio y Ovando, Cristian (2011) La década dorada de las relaciones diplomáticas entre Chile y Bolivia, Tinkazos, Revista Boliviana de Ciencias Sociales, $\mathrm{n}^{\circ}$ 29, pp. 87-108.

Harms, Carlos (1930) Los grandes problemas de la zona norte de Chile. Santiago: La Ilustración.

Huysmans, Jef (2005) «James Der Derian: the unbearable lightness of theory" en: Iver B. Neumann y Ole Wrver, The Future of International Relations Masters in the Making? Londres, Routledge: pp. 361-384.

Jeftanovic (1992) «El síndrome holandés: Teoría, evidencia y aplicación al caso chileno (1901-1940)» Estudios Públicos, n ${ }^{\circ} 45$ :pp. 299-331.

Jessop, Bob. (2004)La economía política de escala y la construcción de las regiones transfronterizas. EURE, vol. XXIX, N ${ }^{\circ}$ 89, p. 25-41.

Memoria del Ministerio de Relaciones Exteriores de Chile (1963.)

Milet, Paz (2004) «Chile-Bolivia: Cien años después, Revista Fuerzas Armadas y Sociedad. Año 18, nº1-2, pp. 37-50.

Montobbio Manuel (2004) «La cultura y los nuevos espacios multilaterales» Pensar Iberoamérica, Revista de Cultura. $\mathrm{N}^{\circ} 7$, septiembre - diciembre. Organización de Estados Iberoamericanos para la Educación, la Ciencia y la Cultura.

Núñez, Andrés, Federico Arenas y Francisco Sabatini, (2013) Producción de fronteras e imaginarios geográficos: de la nacionalización a la globalización de la Cordillera de los Andes. Chile, siglos XX y XXI. En : Fronteras en movimiento e imaginarios geográficos La cordillera de Los Andes como espacialidad socio-cultural, Instituto de Geografía, Pontificia Universidad Católica de Chile, Santiago RIL, pp.111-136.

Ovando, Cristián y González, Sergio. (2012) «La política exterior chileno-boliviana en la década de 1950 mirada desde la región de Tarapacá: Una aproximación desde el diálogo entre las teorías de las percepciones y el realismo neoclásico». Polis, vol.11, n.32, pp. 461-492.

Pinochet de la Barra, Oscar (2004), Chile y Bolivia: hasta cuando, Santiago: LOM Ediciones.

Prudencio, Ramiro (2006), «La cuestión marítima boliviana en la actualidad». Revista Universum, vol.21, nº 1, pp. 231-239.

Salomón, Mónica (2002), «La teoría de las relaciones internacionales en los albores del siglo XXI: diálogo, disidencia y aproximaciones. Cidob d'afers internationals, n. 56. Sempat Asadourian, Carlos (1982) El sistema de la economía colonial. Mercado interno, regiones y espacio económico. Lima, Instituto de Estudios peruanos.

Vargas, Andrés (2013), "Reinterpretando la diplomacia de los Pueblos", Trabajos $y$ ensayos $\mathrm{N}^{\circ} 17$, Departamento de Derecho Internacional Público, Relaciones Internacionales e Historia del Derecho, Universidad del País Vasco.

Zaldivar, A. 1923, El ferrocarril a Salta y la agricultura nacional. Antofagasta, Imprenta Skarnic.

\section{Prensa}

El Pueblo de Iquique

El Tarapacá de Iquique

El Muro Nacional de La Paz

La Patria de Oruro 